\title{
A Brief Study on the Implication of Constructivism Teaching Theory on Classroom Teaching Reform in Basic Education
}

\author{
Qiong Jia \\ Normal College, Shihezi University, Shihezi 832003, China \\ E-mail: cherry_0203@163.com
}

\begin{abstract}
Constructivism learning theory is the further development as behaviorism arrives at cognitivism. According to its teaching theory: knowledge is uncertain; the learning process of knowledge is also the construction process of knowledge; students are the main body of learning activity and they construct knowledge on their own initiatives; teachers are the helpers and the drivers for students constructing knowledge. These views generate more implications for China's teaching reform, what affect the reform of learning theory and teaching theory in a sense and turn into the theoretical base for China's education reform. This paper tries to probe into the implication of constructivism teaching theory on China's basic education.
\end{abstract}

Keywords: Constructivism, Learning theory, Basic education, Implication

Constructivism, as a new cognitive theory, has been introduced in China since late $80 \mathrm{~s}$ and early $90 \mathrm{~s}$ in $20^{\text {th }}$ century, exerting a significant effect on the education field. The development from behaviorism to cognitivism to constructivism is not only a leap of epistemology and a progress of learning psychology, and also a revolution of traditional education. Constructivism's profound and unique recognition to human learning make the traditional teaching thought change thoroughly, generating a deep effect on teaching practice. In recent years, Chinese scholars introduce the constructivism theory sufficiently and make systematic studies, producing amounts of rich research fruits. The author thinks that the constructivism teaching theory has an important guiding effect on China's basic education reform. This paper tends to probe into the implication of constructivism teaching theory on China's basic education and teaching.

\section{The origin of constructivism}

Any theory has its basis and background. Constructivism learning theory is not an exception. Its origins mainly include philosophy and psychology.

\subsection{The philosophy origin}

Constructivism, as a new thought, is a new learning philosophy. Some people agree that the first constructivist is Socrates. His "hippcrates" is a successful model for constructivism teaching. Kant's studies on the integration of rationalism and empiricism indicate kind of constructivism. In his opinion, the subject can not open toward the external world directly. Only by the constructed-internally principal cognitive rules, the subject can organize experiences and develop knowledge. Later, along with the transfer of structuralism methodology toward post-structuralism, the absolute status of rationalism is broken further. Constructivism learning theory comes into being from the development of cognitivism, turning into a new learning theory.

\subsection{The psychology origin}

In perspective of psychology, the first who contribute a lot to the development of constructivism thought and apply it to classes and students' learning and development are Dewey, Piaget, and Vygotsky. Dewey advances the experimental learning theory, emphasizing on the generation and reform of experiences. Switzerland Famous psychologist Piaget is taken as the forerunner of modern constructivism. In 1972 Piaget puts forward the concepts of "assimilation" and "conformability". In his opinion, the recognition means the subject affects the object by his unique recognition structure, achieving a balance between the subject and the object. Based on psychological ideas, Piaget thinks that all knowledge has the external origin and students' cognitive development is actualized naturally in the process of receiving knowledge. During $70 \mathrm{~s}$ and $80 \mathrm{~s}$ in $20^{\text {th }}$ century, Russia excellent psychologist Vygotsky founds the base for the formation of modern constructivism. According to his idea, learning is a social construction. Individual learning is under certain history and social background.

\section{Basic ideas of constructivism learning theory}

\subsection{On knowledge}

Knowledge is only an explanation and an assumption but not the final answer for all questions. In contrast, it will be discarded along with the human process and new assumption will appear. Besides, knowledge can not 
summarize the world rules precisely. In other words, we can not apply knowledge to certain problems directly. We have to analyze certain issue based on practical conditions. In addition, constructivists agree that knowledge can not live on its physical form and out of specific entity. Although language and signals endow knowledge with certain forms, it does not mean learners have same understandings toward these statements, just as one hundred people will have one hundred different understandings toward Hamlet. These understandings are based on individual learners' experiences and backgrounds, what is determined by specific learning experience.

\subsection{On learning}

Learning is the process that individuals construct their cognitive structures. "Construction" is a kind of initiative, conscious, and self-organized recognition way. It is the "interaction" between the subject and the object. The learning process is the construction of knowledge. Learning is an initiative construction and the generation of meanings. This process is completed by the interaction of learners' old and new knowledge. In other words, pure external stimulation is meaningless. Only when learners code, process, and construct their unique understandings based on their previous experiences, can it be real learning.

\subsection{On students}

Students enter classrooms with their rich previous experiences. They hold their opinions toward daily life and even universal issues. Even though they do not know some issues and have no experiences, they may form special explanations and assumptions based on previous experiences and cognitive abilities as some issues appear. That is not illogical guess but logical assumption based on previous experiences. Therefore, teaching should take students' previous knowledge and experience as the growth point of new knowledge, and introduce students to generate new knowledge from the former.

\subsection{On teachers}

As we emphasize on the students as the subjects, we should change the role of teachers, from the initiator and the indoctrinator into the helper and the driver for students constructing meanings initiatively. In other words, teachers should be the designer of teaching environment, the guider for students' learning, and the academic consultant for students. It discards the traditional teaching mode that takes teachers as the center, which merely focuses on conveying knowledge, regarding students as the object for receiving knowledge. The new teaching mode takes students as the center, under the guidance of teachers. Teachers organize and guide the whole teaching process.

\section{Implication of constructivism theory on classroom teaching in basic education}

Based on analysis above, we know that constructivism learning theory puts forward new explanations for learning and teaching. According to this theory, students are the subject in teaching. Teachers should offer more humanism cares for students and create a favorable teaching environment for students. It emphasizes on the initiatives and the interaction in teaching. Students should focus on exploration learning and cooperative learning based on previous knowledge and experiences by means of interactive actions. By this way, students can improve their cognitive ability continuously. Teachers can help students form the positive technique, the affection, the attitude, and the habit in learning. All these innovative ideas constitute the complete constructivism teaching theory system, which contribute a lot to modern teaching theory. Constructivism teaching theory has important meanings for China's basic education that focuses on improving students' comprehensive quality.

(1) Reform the teaching views. Pro. Lan Ye has said: "Today's teaching reform should change not only the teaching theory but also the teachers' teaching views, together with teachers' daily teaching activities." In the traditional teaching mode, teachers explain, analyze, and introduce too much. Students receive knowledge passively. They have few time and space for thinking. The traditional mode neglects students' practicing process and just input fixed things into students. As a result, students will refuse to think by themselves. This mode taking teachers' teaching as the center is not good for developing students' potentials and their development. In contrast, the constructivism agrees that learning is initiative and positive. In learning, students are the subject of teaching. Without students' initiative participation, the learning is meaningless. In teaching, teachers are the subject of teaching. Teachers mean to inspire and guide students to learn knowledge effectively.

(2) Emphasize on cooperation and communication and train students' cooperative consciousness. In traditional teaching, the cooperation between teachers and students, students and students are neglects. Constructivism agrees that knowledge is the social construction of individuals and others by negotiation. Therefore, in the process of constructing knowledge, students must cooperate and communicate with others. In a cooperation and communication environment, students can enlarge their views, instead of receiving knowledge passively. It can help them to build up their own knowledge system, cultivate their innovative spirit and problem-solving ability. 
Meanwhile, it can make them respect others' opinions and ideas.

(3) Students' previous knowledge, experiences, thinking mode, learning habits and methods are the start for teaching. Modern cognitive psychology shows that learning is an interactive process of new knowledge and old knowledge. The former knowledge and techniques stored in the memory system are important internal conditions for generating study activities. Ausubel, in perspective of meaning study, gives priority to students' original knowledge in learning. He said: "If I conclude all educational psychology into one principle, it will be that the only important factor affecting study is what learners have known. Knowing about this point, the teaching will be effective." Constructivism learning theory illustrates this point deeply. Learning is an initiative process based on students' previous knowledge and experiences. Before the class, teachers should prepare for two fields. Firstly, compare and analyze the curriculum standards and textbooks, and confirm the teaching targets. Make best use of textbooks flexibly. Secondly, analyze and understand students, and know students' previous knowledge and experiences. Therefore, we advocate that teachers should take students' previous knowledge and experiences as the growth point for new knowledge during the process of teaching. Guide students to produce new knowledge and experience from original ones, achieving the mutual connection of new and old knowledge.

(4) Teaching should be changed from authoritative conducting to equal association and communication. In traditional teaching, teachers are at a sovereign authoritative position. They do not respect or care for students as necessary, which leads to a gap between teachers and students, and even stimulates conflicts. Ancient men said: "People with more knowledge are teachers and with morals are examples." Teachers should give students more respects, one more chance, and one more trust, building a kind and harmonious relations. Teachers should treat students with an equal, kind and considerate attitude, supplying a loose environment for students' learning. Then, students can learn to communicate with teachers and response to teachers' praises and criticizes, which can greatly improve the relations between teachers and students. Construct a democratic and equal teacher-student relation.

(5) Create a better teaching environment. Constructivism learning theory requires to study in real or semi-real environment, emphasizing on non-structural knowledge or students' previous experiences. Traditional teaching focuses on structural knowledge but not non-structural knowledge and students' life experiences. Therefore, in teaching, we should create an interactive learning environment for students by modern teaching media, helping students to explore and discover new knowledge. Students should solve problems by themselves. Build a bridge between new knowledge and students' previous knowledge, which can improve students' ability of solving problems.

To sum up, constructivism teaching theory has already turned into a hot inside and outside, which advances many new thoughts and views. We should judge and absorb them reasonably, dealing with sorts of relations properly, including the subjectivity and objectivity of knowledge, the transfer and construction of knowledge in learning, teachers' guidance, and students as the center, and applying relevant theory to basic education teaching properly.

\section{References}

Chen, Qi \& Zhang, Jianwei. (1998). An analysis on the Key of Constructivism Instructional Theory. Journal of East China Normal University: Educational Sciences. No.1.

Ding, Yuankun. (2003). Constructivism teaching theory and the implication. Journal of Shenyang College of Education. No.3. p165-167.

Kong, Xiansui. (2002). The implications of constructivism theory on teaching. Research on Education Tsinghua University. No.1.p132.

Ma, Guolin. (2005). Teaching study on the reform of primary education. Future and Development. No.4. p63-64.

Yang, Chunhong \& Zhang, Chunsheng. (1998). Constructivism and reform of basic education. Journal of Hebei Normal University: Education Studies. No.3. p38.

Zheng, Yuxin. Wang, Changpei \& Zhang, Guojie. (1994). Views of constructivism theory. Journal of Mathematics Education. No.5. p9-14.

Zhong, Zhixian. (2002). Core thoughts of constructivism teaching idea. China Educational Technology. No.2. p17-18.

Zou, Yanchun. (2002). On the constructivism learning theory's development origins and logic starts. Studies in Foreign Education. No.5. 